\title{
Concepções sobre a Natureza da Ciência: a trajetória dos estudantes de uma disciplina sobre Evolução dos Conceitos da Física+*1
}

Fábio Luís Alves Pena ${ }^{2}$

Instituto Federal de Educação, Ciência e Tecnologia da Bahia

Campus Simões Filho

Simões Filho - BA

Programa de Pós-graduação em Ensino, Filosofia e História das Ciências UFBA/UEFS

Elder Sales Teixeira ${ }^{3}$

Universidade Estadual de Feira de Santana

Programa de Pós-graduação em Ensino, Filosofia e História das Ciências UFBA/UEFS

Feira de Santana - BA

\section{Resumo}

Apresentamos aqui um estudo de caráter qualitativo e descritivo sobre a trajetória dos estudantes de uma disciplina sobre Evolução dos Conceitos da Física, turno noturno, ministrada no $1^{o}$ semestre acadêmico do ano letivo de 2012, de um curso de graduação em Física, quanto às suas concepções acerca da Natureza da Ciência (NdC). Os dados para a investigação foram obtidos a partir da observação sistemática das aulas, gravadas em áudio e vídeo, transcritas para um protocolo e depois analisadas. Um diário de campo também foi utilizado para o registro dos dados. As concepções dos estudantes sobre a NdC foram identificadas e analisadas tendo como parâmetro a visão de ciência defendida/problematizada pelo professor. Os resultados mostram que as trajetórias individuais dos referidos estudantes, quanto às suas concepções sobre a $\mathrm{NdC}$, podem ser

\footnotetext{
${ }^{+}$Conceptions about the Nature of Science: the path of the students in a course on the Evolution of the Concepts of Physics

* Recebido: maio de 2016. Aceito: novembro de 2016.

${ }^{1}$ Uma versão preliminar deste trabalho foi apresentada no X Encontro Nacional de Pesquisa em Educação em Ciências, X ENPEC, Águas de Lindóia, SP, 24 a 27 de novembro de 2015.

2 E-mail: fb.pena@gmail.com

3 E-mail: eldersate@gmail.com
} 
agrupadas da seguinte forma: a) estudantes que revelaram, explicitamente, uma concepção que não concordava com a visão defendida/problematizada pelo professor, mas que apresentou mudança ao longo da disciplina; b) estudantes que discordaram de aspectos relativos à visão do professor, mas não apresentaram um padrão de mudança no decorrer das aulas; c) estudantes que expuseram questionamentos elou posicionamentos ao longo das aulas, que claramente sinalizavam concepções sobre a $\mathrm{NdC}$ em acordo com a visão de ciência defendida/problematizada pelo professor, mas no final da disciplina, aqueles que responderam ao questionário aplicado revelaram, direta ou indiretamente, que tinham concepções "errôneas" sobre o fazer científico, tendo como parâmetro a visão do professor; $d$ ) estudantes que mesmo atentos às discussões de natureza histórico-epistemológicas que ocorreram durante as aulas, quase que não expuseram questionamentos elou posicionamentos, ao longo da disciplina, que explicitamente sinalizassem suas concepções sobre a NdC.

Palavras-chave: Evolução dos Conceitos da Física; Concepções sobre a Natureza da Ciência; Futuros profissionais em Física.

\begin{abstract}
It is presented here a descriptive and qualitative study about the trajectory of students in a course on the Evolution of Physics Concepts, a night course given in the first academic semester in 2012 in a Physics undergraduate course, regarding their conceptions about the Nature of Science (NoS). This research also aims to investigate the teacher's influence on the discipline in these conceptions. The data to the investigation were obtained through the systematic observation of classes, recorded in audio and video, transcribed according to a protocol and then analyzed. A field diary was also used to register data. The students' conceptions about NoS were identified and analyzed considering the vision of science defended/problematized by the teacher as a parameter. The results show that the individual trajectory of the previously mentioned students, related to their conceptions about NoS, can be grouped in the following way: a) students that explicitly revealed discordance to the vision defended/ problematized by the teacher, but presented changes throughout the course; $b$ ) students that disagreed with aspects related to the teacher's view but did not present a change pattern throughout the classes; c) students that exposed questionings/ positioning throughout the classes that clearly revealed conceptions about NoS in accordance with
\end{abstract}


the vision of science defended/ problematized by the teacher, but in the end of the discipline, those who responded the applied questionnaire revealed, direct or indirectly, that they had "erroneous" conceptions about the scientific achievement, having the teacher view as parameter; d) students that, even aware to the historical epistemological nature of the discussions occurred during the classes, hardly exposed questionings/ positioning, throughout the discipline, that explicitly showed their conceptions about the NoS.

Keywords: Evolution of the Concepts of Physics; Conceptions about the Nature of Science; Future professionals in Physics.

\section{Introdução}

Segundo Ferreira e Martins (2012), a expressão Natureza da Ciência (NdC), geralmente, é usada por pesquisadores para se referir a questões, tais como: o que a ciência é, como funciona, como os cientistas atuam como grupo social, como a sociedade influencia e reage aos empreendimentos científicos etc.

Na literatura educacional (a exemplo de FERREIRA; MARTINS, 2012; FORATO; MARTINS; PIETROCOLA, 2012) existem recomendações consideradas pertinentes para o uso da História e Filosofia da Ciência (HFC) na educação visando a discussão, em geral, dos seguintes aspectos da NdC: compreensão da ciência como elemento cultural; sucesso no aprendizado de conteúdos da ciência; satisfação dos estudantes ao aprender sobre $\mathrm{NdC}$; defesa de que sua presença humaniza o ensino de ciências; compreensão das normas da comunidade científica; compreensão do significado, produção, correlações, possibilidades e limitações do conhecimento; problematização da visão exclusivamente empírico-indutivista da construção da ciência; possibilidade de conhecimento metodológico, permitindo refletir sobre as relações e diferenças entre observação e hipóteses, leis, explicações e, principalmente, resultados experimentais e explicação teórica; compreensão da ciência como construção humana e sua relação com outros campos do conhecimento, incluindo as diversas manifestações artísticas; manipulação e entendimento da tecnologia, entre outros.

Conforme Massoni e Moreira (2012), a literatura na área de pesquisa em Ensino de Ciências que tem foco na Epistemologia e também na História da Ciência apresenta uma riqueza de trabalhos sobre distintos aspectos associados com a NdC:

A - Propostas e argumentações que objetivam promover discussões sobre a $\mathrm{NdC}$, tanto nos cursos de formação de professores quanto nas aulas do Ensino Médio como forma de melhorar e contextualizar historicamente o ensino e tornar os conceitos de Física mais acessíveis;

B - Estudos que visam identificar as concepções epistemológicas de estudantes e de professores de ciências e propõem estratégias para transformá-las; 
C - Pesquisas acerca da importância de se ensinar os conteúdos da Física falando também sobre a Física e assim estimular a formação de cidadãos mais críticos e reflexivos.

No que concerne aos resultados de pesquisa relativos ao item $\mathrm{B}$, os professores de ciências (GIL-PÉREZ et al., 2001) e os futuros profissionais em Física apresentam concepções indesejáveis sobre a NdC (MOREIRA; MASSONI; OSTERMANN, 2007; MASSONI; MOREIRA, 2007; FERREIRA; MARTINS, 2012) tendo em vista as discussões atuais em educação em ciências e em epistemologia da ciência, seja por desconhecimento ou por resistência (CORDEIRO; PEDUZZI, 2012).

De acordo com Oliveira e Silva (2012), a inclusão da História da Ciência (HC) vem sendo recomendada como um recurso para o ensino e aprendizagem de aspectos epistemológicos da construção da ciência. Essa discussão, segundo Ferreira e Martins (2012), é bastante limitada, quer seja na formação dos licenciandos, quer seja dos bacharelandos das áreas científicas, tanto no exterior como no Brasil.

Existem recomendações da literatura na área de Pesquisa em Ensino de Ciências para a inserção de questões sobre a $\mathrm{NdC}$, seus procedimentos, desafios e limitações de modo a levar os estudantes a refletirem sobre o processo de construção do conhecimento científico (VITAL; GUERRA, 2014), bem como consenso entre pesquisadores brasileiros em Ensino de Física no que se refere à importância da discussão sobre a NdC nesse ensino (VILAS BOAS et al., 2013). Apesar disso, discussões desse tipo ainda são bastante incipientes na sala de aula (PEDUZZI; TENFEN; CORDEIRO, 2012).

Nesse contexto, a formação dos professores é assinalada como o principal obstáculo a ser enfrentado para a transposição da HFC para a sala de aula (LEDERMAN, 1992, 1999; MATTHEWS, 1998, KÖHNLEIN; PEDUZZI, 2005; HÖTTECKE; SILVA, 2011; FORATO; MARTINS; PIETROCOLA, 2012).

Observa-se também que os trabalhos sobre o uso didático da HFC, publicados em periódicos nacionais especializados em Ensino de Ciências e em Ensino de Física, que buscam investigar as possíveis mudanças que elementos de uma disciplina específica conseguem promover, por influência do uso da HFC, nas concepções dos estudantes sobre a NdC, quase sempre utilizam um pré-teste aplicado no início da disciplina e um pós-teste aplicado no final dessa (TEIXEIRA; GRECA; FREIRE JR, 2012).

Isso, por si só, limita os resultados desses trabalhos e das pesquisas sobre as possíveis mudanças que uma disciplina sobre HFC consegue promover, por influência do uso da abordagem histórico-filosófica, nas concepções dos estudantes sobre a NdC, uma vez que a análise das respostas pode oferecer apenas indícios pontuais sobre as noções dos participantes (GATTI; NARDI; SILVA, 2010) por se tratar de dados que enfocam apenas o produto final, ou a comparação entre pré e pós-testes, sem a devida valorização do processo vivenciado na realização da intervenção educacional (FORATO; MARTINS; PIETROCOLA, 2012).

Aqui relatamos os resultados de um estudo de caráter qualitativo e descritivo sobre a trajetória dos estudantes, quanto às suas concepções sobre a $\mathrm{NdC}$, de uma disciplina sobre ECF, 
ministrada no $1^{\circ}$ semestre acadêmico do ano letivo de 2012, de um curso de graduação em Física, modalidade presencial (licenciatura - curso noturno; bacharelado - curso diurno), ao longo das 32 aulas da disciplina.

A ênfase nas trajetórias individuais dos estudantes é para explorar com maior detalhe o processo em si e não apenas o produto final, ou a comparação entre pré e pós-testes.

Para tanto, além dos dados relativos às observações do contexto de sala de aula, também foram usadas as informações, referentes aos estudantes inscritos na disciplina, extraídas do questionário aplicado, do sistema virtual de apoio aos cursos presenciais ${ }^{4}$ e do diário de campo.

\section{Contexto e Metodologia}

A disciplina ECF em foco apresenta carga horária de 72 horas na estrutura curricular dos cursos de licenciatura e de bacharelado em Física, sendo cursada obrigatoriamente e em conjunto por estudantes desses dois cursos ao final da formação. É a única disciplina desse curso de graduação em Física que compulsoriamente apresenta os conteúdos por meio de uma abordagem histórico-conceitual (sobre a origem e desenvolvimento dos conceitos físicos) e numa perspectiva epistemológica (no sentido de procurar formar uma visão "adequada"5 sobre a NdC). Estrutura-se, basicamente, segundo cinco livros, que abordam um amplo espectro de conceitos e teorias da Física, suas gêneses e seus desenvolvimentos, do nascimento da ciência, com os gregos do século VI a.C., à Física dos quarks.

As aulas da disciplina eram ministradas nas segundas e quintas-feiras, agrupando-se em 2 horas-aula (duração de 50 minutos cada hora-aula) consecutivas em cada dia, sempre das $20 \mathrm{~h} 20 \mathrm{~min}$ às $22 \mathrm{~h} 00 \mathrm{~min}$, totalizando 4 horas-aula semanais durante o $1^{\circ}$ semestre acadêmico do ano letivo de 2012.

A turma observada e gravada era composta por 19 estudantes inscritos, na qual acompanhamos a trajetória desses estudantes, quanto às suas concepções sobre a $\mathrm{NdC}$, a partir da observação sistemática das aulas, totalizando 64 horas-aula de observação. Dos 19 estudantes inscritos na disciplina, semestre acadêmico 2012.1, 10 eram estudantes do curso de licenciatura e 9 do curso de bacharelado.

A estratégia de ensino utilizada pelo professor se baseava em exposições dialógicas/participativas a partir de leitura pré-selecionada do livro de textos, slides, vídeos, seminários, simulação, animação e/ou videoaula sobre episódios da história da Física.

\footnotetext{
${ }^{4} \mathrm{O}$ primeiro autor desse trabalho teve acesso, como convidado, às informações publicadas no sistema de apoio aos cursos presenciais (plataforma moodle).

${ }^{5} \mathrm{O}$ uso da HFC como forma de proporcionar visões adequadas sobre a NdC, ou de transformar visões distorcidas sobre a NdC, tendo como orientação os itens listados pela visão de consenso, não mostra-se coerente segundo as críticas sofridas por essa visão (ALTERS, 1997; IRZIK, NOLA; 2011, 2014), e porque também não há consenso entre pesquisadores em Ensino de Ciências sobre a ocorrência de mudança/transformação das concepções de estudantes sobre a NdC por influência da abordagem histórico-filosófica (TEIXEIRA; GRECA; FREIRE JR, 2012).
} 
Para análise da trajetória dos estudantes, utilizamos informações pessoais e acadêmicas dos estudantes inscritos na disciplina ECF, semestre 2012.1, suas opiniões, posicionamentos e comentários referentes às visões sobre a $\mathrm{NdC}$ e dados do questionário direcionado aos mesmos. Dos 19 estudantes, 8 ( 5 da licenciatura e 3 do bacharelado) não preencheram o questionário aplicado.

O questionário aplicado foi elaborado com base no instrumento construído, previamente validado e aplicado por Martins $(2007)^{6}$, e a partir das observações das aulas da disciplina ECF. Isso porque procuramos um instrumento que permitisse investigar as trajetórias individuais dos estudantes e a influência do professor da disciplina nessa trajetória.

No trabalho, Martins relata os resultados de uma pesquisa empírica, de natureza diagnóstica, que buscou investigar as principais dificuldades e experiências de três grupos de indivíduos (licenciandos, estudantes de pós-graduação e professores da rede pública) acerca do uso da HFC para fins didáticos.

No que diz respeito aos dados empíricos para descrever a trajetória dos estudantes ao longo das 32 aulas da disciplina (semestre acadêmico 2012.1), foram tomados os devidos cuidados éticos, dentre eles, o esclarecimento aos estudantes sobre a pesquisa e o uso do Termo de Consentimento Livre e Esclarecido (TCLE). Para preservar a identidade dos estudantes optamos por chamar cada estudante pela letra "E" seguida de um número correspondente.

Durante a investigação o professor conduziu as aulas da disciplina e o primeiro autor do presente artigo coletou (como observador), gravou (em áudio e em vídeo) e transcreveu os dados sobre as aulas (a exemplo da aula 08 em anexo). Uma câmera, um gravador e um diário de campo foram utilizados no registro dos dados. Esses foram transcritos e transferidos para o seu respectivo mapa de episódio (seção adiante).

As concepções dos estudantes sobre a $\mathrm{NdC}$ foram identificadas e analisadas segundo a visão de ciência defendida/problematizada pelo professor em seus artigos, na sala de aula, videoaula, nos seminários apresentados pelos estudantes e no material didático por ele produzido, isto é: contraposição à concepção puramente indutivista e ateórica e à concepção aproblemática e/ou a-histórica do conhecimento científico; objeção à concepção metodologicamente rígida do fazer científico e à concepção exclusivamente analítica do conhecimento científico; contraposição à concepção puramente acumulativa (de crescimento linear) e à concepção individualista e elitista do conhecimento científico; bem como a objeção à concepção socialmente neutra e descontextualizada do fazer científico.

Os aspectos a seguir foram utilizados como parâmetro para captar as concepções dos estudantes sobre a $\mathrm{NdC}$ :

\footnotetext{
${ }^{6}$ Questões 3.1, 3.2, 3.4, 3.5 e 3.6. A saber: 3.1 Você se interessa por HFC? Por quê? 3.2 Além da disciplina ECF, você já fez alguma disciplina ou curso envolvendo HFC? Caso sim, qual(is)? 3.4 Você acha importante que a HFC esteja presente na formação do futuro profissional em física (licenciando ou bacharelando)? Por quê? $3.5 \mathrm{Na}$ sua opinião, quais são as principais dificuldades para se trabalhar com HFC no ensino de física? 3.6 Você, como professor(a), já tentou/tentará trabalhar elementos de HFC em suas aulas? Por quê? Que tipo de atividade realizou/pretende realizar?
} 
- Contraposição à concepção puramente indutivista e ateórica do conhecimento científico, isto é, objeção à concepção que destaca o papel 'neutro' da observação e da experimentação (não influenciadas por ideias apriorísticas), esquecendo o papel essencial das hipóteses como orientadoras da investigação, assim como dos corpos coerentes de conhecimentos (teorias) disponíveis, que orientam todo o processo (GIL-PÉREZ et al, 2001). Contraposição à ideia de um método empírico universal, elaborado unicamente a partir da experiência, baseado em um enfoque no qual o conhecimento advém da generalização indutiva a partir da observação, sem qualquer influência teórica ou subjetiva, e dessa forma supostamente capaz de assegurar a verdade absoluta às afirmações científicas (MOREIRA; MASSONI; OSTERMANN, 2007), desconsiderando o papel da teoria, das hipóteses como norteadores do processo investigativo (DANIEL; PEDUZZI, 2009), bem como o fato de que os conceitos que a ciência utiliza é para formular explicações e modelos de que é feito o mundo e de como ele se comporta. Nossas observações e dados sobre fenômenos que observamos são dependentes do que já sabemos e de nossas interpretações e inferências sobre o significado desses dados e observações (FIGUEIRÊDO E PAULA; BORGES, 2008). As observações são carregadas de teorias (FERREIRA; MARTINS, 2012), uma observação significativa não é possível sem uma expectativa preexistente (FORATO; MARTINS; PETROCOLA, 2012), a teoria precede a observação que por si só, não é fonte de conhecimento (MOREIRA; MASSONI; OSTERMANN, 2007);

- Objeção à concepção aproblemática e/ou a-histórica do conhecimento científico, ou seja, contraposição a transmissão dos conhecimentos já elaborados, sem mostrar os problemas que lhe deram origem, qual foi a sua evolução, as dificuldades encontradas etc, não dando igualmente a conhecer as limitações do conhecimento científico atual nem as perspectivas que, entretanto, se abrem (GIL-PÉREZ et al., 2001). Os problemas, longe de serem encarados como empecilho, colaboram para o desenvolvimento científico (CORDEIRO; PEDUZZI, 2010), historicamente determinado;

- Contraposição à concepção metodologicamente rígida do fazer científico, isto é, refere-se à forma como se concebe a realização de uma dada investigação, contrapondo-se à visão que apresenta o "método científico" como um conjunto de etapas a seguir mecanicamente e a imagem que destaca o que se supõe ser um tratamento quantitativo, com controle rigoroso etc, esquecendo - ou, inclusive, recusando - tudo o que se refere à criatividade, ao caráter tentativo, à dúvida (GIL-PÉREZ et al., 2001). O conhecimento científico não é absolutamente provado e objetivo, pois ele não corresponde à realidade tal como ela é, uma vez que temos uma percepção limitada do universo, assim como as explicações e proposições elaboradas nas ciências são povoadas por entidades teóricas e baseadas em modelos e situações idealizadas, fruto da imaginação e criatividade dos cientistas, uma das razões pelas quais o conhecimento científico é sempre provisório (FIGUEIRÊDO E PAULA; BORGES, 2008). Um processo elaborado pelos homens, sujeito a erros, revisões e avanços (LONGHINI; NARDI, 2009), baseia-se fortemente, mas não inteiramente, na observação, evidência experimental, 
argumentos racionais e ceticismo, teorias científicas não podem ser provadas e não são elaboradas unicamente a partir da experiência (FORATO; MARTINS; PIETROCOLA, 2012): o conhecimento científico tem natureza imaginativa, criativa, conjetural, hipotética e tentativa (MOREIRA; MASSONI; OSTERMANN, 2007);

- Objeção à concepção exclusivamente analítica do conhecimento científico, isto é, objeção à divisão parcelar dos estudos, o seu caráter limitado, simplificador (GIL-PÉREZ et al, 2001), à compartimentação dos estudos. Tal concepção esquece os esforços posteriores de unificação e de construção de corpos coerentes de conhecimentos cada vez mais amplos, ou o tratamento de 'problemas-ponte' entre diferentes campos de conhecimento que podem chegar a unificar-se, como já se verificou tantas vezes e que a HC evidencia (GIL-PÉREZ et al., 2001). Há por trás de pesquisas pontuais diversos esforços para teorias unificadoras (CORDEIRO; PEDUZZI, 2010);

- Contraposição à concepção puramente acumulativa (de crescimento linear) do conhecimento científico, ou seja, objeção à interpretação simplista da evolução dos conhecimentos científicos, para a qual o ensino pode contribuir ao apresentar os conhecimentos hoje aceites sem mostrar como eles foram alcançados, não se referindo às frequentes confrontações entre teorias rivais, às controvérsias científicas, nem aos complexos processos de mudança (GIL-PÉREZ et al., 2001). O processo de substituição de teorias aceitas por novas teorias como o resultado de um processo social de negociação para alcançar consenso sobre qual das teorias competidoras melhor explica os fatos e qual delas supostamente exibe maior potencial em termos de pesquisas futuras (FIGUEIRÊDO E PAULA; BORGES, 2008), bem como os conjuntos de conceitos e teorias que evoluem, não são imutáveis (MOREIRA et al., 2007). Há a constante possibilidade de desacordo entre os cientistas (FERREIRA; MARTINS, 2012), a natureza não fornece dados suficientemente simples que permitam interpretações sem ambiguidades (FORATO; MARTINS; PIETROCOLA, 2012);

- Objeção à concepção individualista e elitista do conhecimento científico, isto é, objeção à visão de que os conhecimentos científicos aparecem como obras de gênios isolados, ignorando-se o papel do trabalho coletivo e cooperativo, dos intercâmbios entre equipes. Em particular, faz-se crer que o conhecimento científico é descoberto por cientistas brilhantes que, em geral, trabalham solitariamente em seus laboratórios (FIGUEIRÊDO E PAULA; BORGES, 2008); de que os resultados obtidos por um só cientista ou equipe podem ser suficientes para verificar, confirmando ou refutando, uma hipótese ou toda uma teoria (GIL-PÉREZ et al., 2001). O conhecimento científico é um processo cooperativo, uma construção humana e coletiva (MOREIRA et al., 2007; FERREIRA; MARTINS, 2012);

- Contraposição à concepção socialmente neutra e descontextualizada do fazer científico, ou seja, contraposição à visão que esquece as complexas relações entre ciência, tecnologia, sociedade (CTS) e proporciona uma imagem deformada dos cientistas como seres fechados em torres de marfim e alheios à necessidade de fazer opções (GIL-PÉREZ et al., 2001). Como se a prática científica não sofresse influência de valores e interesses, de aspectos 
econômicos, sociais, políticos, culturais e históricos, ideológicos, isto é, como se fossem fatos históricos isolados de seu contexto (LONGHINI; NARDI, 2009), a ciência é uma atividade humana influenciada pelo contexto sociocultural de cada época (FORATO; MARTINS; PIETROCOLA, 2012).

\section{Os mapas de episódio}

Os dados obtidos das observações das aulas e das anotações no diário de campo foram sistematizados segundo a ferramenta metodológica denominada "mapas de episódio". Essa ferramenta de análise foi elaborada por Amantes e Borges (2011) para uma análise exploratória do contexto de ensino de aulas de Física de uma escola pública federal, com o intuito de descrever a situação de ensino e levantar possíveis fatores que influenciam o entendimento dos conteúdos estudados; abrangem-se também os parâmetros da turma e os específicos dos grupos, uma vez que a dinâmica se alterou entre trabalhos em conjuntos e explanações do professor.

Os mapas de episódio constituem-se de indicações de trechos das gravações em que houve discussão sobre o conteúdo ou a unidade de análise, relatos a respeito das atividades e da condução das aulas pelo professor, além de explicitar, para cada aula, as características do comportamento de cada grupo (AMANTES; BORGES, 2011).

Segundo Amantes e Borges (2011), a ferramenta "mapas de episódio" se reporta tanto às características gerais como específicas e também a episódios relevantes para as questões de pesquisa, podendo ser utilizada de muitas maneiras para avaliar diferentes parâmetros do contexto de ensino. Ainda que não compreenda transcrições, a ferramenta mapeia toda a unidade de análise qualitativa, localizando os episódios por demarcações específicas.

Os "mapas de episódio" constituem-se de informações e descrições gerais da aula, em ordem cronológica; de acontecimentos da aula, que explicitam os eventos mais significativos, bem como da dinâmica geral de condução do professor; de uma sucinta descrição do comportamento dos estudantes (AMANTES; BORGES, 2011); de transcrições dos trechos das gravações em que houve participação do(s) estudante(s) e/ou do professor no que diz respeito à sua visão sobre a $\mathrm{NdC}$.

No quadro 01, adiante, constam tópicos relativos ao número e à data da aula, atividades didáticas desenvolvidas, materiais de apoio, enfoque metodológico, conteúdo trabalho/episódio histórico, à duração da aula, ao intervalo de tempo decorrido na gravação da fala dos estudantes e do professor, ao contexto de ensino, aos posicionamentos, perguntas, comentários e/ou opiniões que afloraram concepções dos estudantes sobre a $\mathrm{NdC}$ e à visão epistemológica defendida/problematizada pelo professor. 
Quadro 01: Modelo do mapa de episódio construído para a pesquisa.

\begin{tabular}{|c|c|c|c|c|}
\hline Aula/Data & $\begin{array}{c}\text { Atividade(s) } \\
\text { didática(s) } \\
\text { desenvolvida(s) }\end{array}$ & $\begin{array}{l}\text { Material(is) } \\
\text { de apoio }\end{array}$ & $\begin{array}{c}\text { Enfoque } \\
\text { metodológico }\end{array}$ & $\begin{array}{c}\text { Conteúdo } \\
\text { trabalhado/episódio } \\
\text { histórico }\end{array}$ \\
\hline Duração & \multicolumn{4}{|c|}{$\begin{array}{l}\text { Contexto de ensino } \\
\text { (observações gerais) }\end{array}$} \\
\hline $\begin{array}{c}\text { Momento da } \\
\text { aula/Intervalo de } \\
\text { tempo decorrido } \\
\text { na gravação } \\
\text { (vídeo/áudio) }\end{array}$ & Estudante & $\begin{array}{r}\text { Participação } \\
\text { Pergunta } \\
\text { posicionament } \\
\text { referentes à vi }\end{array}$ & $\begin{array}{l}\text { o estudante: } \\
\text { opiniões, } \\
\text { e comentários } \\
\text { sobre a NdC }\end{array}$ & Contexto \\
\hline $\begin{array}{c}\text { Momento da } \\
\text { aula/Intervalo de } \\
\text { tempo decorrido } \\
\text { na gravação } \\
\text { (vídeo/áudio) }\end{array}$ & \multicolumn{3}{|c|}{$\begin{array}{c}\text { Visão sobre a NdC defendida/problematizada } \\
\text { pelo professor }\end{array}$} & Contexto \\
\hline
\end{tabular}

Os dados extraídos da transcrição das manifestações verbais, das ações e dos eventos de sala de aula, gravados em áudio e vídeo, complementados pelas anotações de campo, foram analisados segundo a técnica de análise de conteúdo, uma vez que o presente estudo, parafraseando Moraes e Galiazzi (2013): investe tanto em descrição como em interpretação; tem no esforço compreensivo uma de suas metas, diferente da análise de discurso que não tem na compreensão seu foco principal, mas sim na crítica; é pretensamente objetiva, limitando-se ao manifesto/explícito; valoriza o sujeito e suas manifestações; trabalha com categorias construídas no processo de análise (categorizar significa dar ênfase a uma parte como modo de melhorar a compreensão do todo); e pode tanto operar com teorias a priori quanto com teorias emergentes, entretanto cada vez mais tem assumido a construção de teorias a partir dos dados.

Por se tratar de um estudo de caráter qualitativo e descritivo sobre a trajetória de estudantes, quanto às suas concepções sobre a $\mathrm{NdC}$, por si só já traz dificuldade em estabelecer pontos de convergentes e/ou divergentes com resultados encontrados em outras pesquisas, uma vez que os trabalhos sobre o uso didático da HFC, publicados em periódicos nacionais especializados em Ensino de Ciências e em Ensino de Física, que buscam investigar as possíveis mudanças que elementos de uma disciplina específica conseguem promover, por influência do uso da HFC, nessas concepções, enfocam apenas o produto final, ou a comparação entre pré e pós-testes, e não as trajetórias individuais dos estudantes durante o processo vivenciado. 


\section{Perfil do professor}

Nesta seção apresentamos um perfil do professor da disciplina ECF para melhor entender sua influência nas concepções dos estudantes sobre a $\mathrm{NdC}$ ao longo do processo vivenciado na disciplina ECF. Esse perfil foi construído a partir das questões do instrumento elaborado, previamente validado e aplicado por Pereira e Martins $(2011)^{7}$, e das observações das aulas da disciplina. A saber:

O professor da disciplina ECF tem bacharelado e mestrado em Física, doutorado em Educação na área temática HFC e é autor/coautor de diversas publicações nessa área.

O professor ministra a disciplina ECF há pelo menos 10 anos e era líder de um grupo de pesquisa em História da Ciência e Ensino de Física.

Seu primeiro contato com o conteúdo de HFC foi nos eventos da área e por meio de colegas de trabalho do Departamento de Física. Desse contato, resultou na sua participação em eventos, o levou ao doutorado e à disciplina ECF.

Entre seus projetos de pesquisa estão: uma disciplina optativa que envolve Ensino e História da Física e a reformulação geral dos seus livros de textos (ampliação e revisão dos textos existentes), com base nos estudos por ele realizados e nas pesquisas de mestrado e doutorado dos seus orientandos.

Sua metodologia de trabalho era bem diversificada e contava com materiais/recursos didáticos por ele desenvolvidos e com referências adicionais (resenha, leitura pré-selecionada do livro de textos, seminários, participação dos estudantes nas aulas, uso de Tecnologias de Informação e de Comunicação - TIC, etc.).

O professor assinalava que os docentes da área de Ensino de Física, e não os da área de Física, eram os mais indicados para lecionar a disciplina ECF. A não ser que os docentes da área de Física tenham leituras ou adquirido familiaridade com o assunto.

Ele não tinha dúvida que, por ser uma disciplina de final de curso, ECF faz uma revisão dos conceitos/assuntos discutidos ao longo do curso de graduação em Física, contribui para a formação geral e para a prática profissional dos futuros licenciados e bacharéis em Física, assim como provoca transformações das concepções dos estudantes sobre a $\mathrm{NdC}$.

Sobre a integração entre o conhecimento histórico e o conteúdo de Física, ele afirmava que o conteúdo histórico deveria, sempre que possível, ser contemplado em outra disciplina do curso de graduação em Física. Também sinalizava que a disciplina ECF teria que ser reformulada para ser oferecida em outro período do curso de graduação, pois, apesar de não ser uma

\footnotetext{
${ }^{7}$ No trabalho, Pereira e Martins analisam a estrutura curricular dos cursos de licenciatura em Física e em Química da UFRN no que se refere à inserção de disciplinas de conteúdo histórico e filosófico - isto é, como essas licenciaturas da UFRN têm proposto a inserção da HFC em seus currículos - e apresentam as principais diferenças e semelhanças entre duas disciplinas de conteúdo histórico-filosófico, uma de cada curso, a partir dos dados coletados conforme alguns eixos de análise - perfil do professor-formador; inserção da HFC na estrutura curricular em questão; enfoque teórico e metodológico da disciplina; relação teoria-prática (HFC e o ensino de ciências) - e com base na análise documental, entrevista com os professores e observações das aulas de cada disciplina.
} 
disciplina voltada para o conceito em si, não pode ser desenvolvida sem ele. Por isso, a disciplina deve ter pré-requisito no curso de graduação em Física.

\section{Concepções sobre a NdC discutidas nas aulas}

Dentro do objetivo de relatar a trajetória dos estudantes, quanto às suas concepções sobre a $\mathrm{NdC}$, segue uma síntese das concepções sobre a $\mathrm{NdC}$ discutidas, problematizadas e externalizadas, tanto pelos estudantes quanto pelo professor, nas aulas da disciplina ECF.

A observação das aulas teve início no dia 05/03/12 e se estendeu até o dia 05/07/2012. Na primeira aula (05/03/2012), o professor tratou de questões relativas à disciplina ECF (objetivo, material didático, conteúdo, metodologia, avaliação, sistema virtual de apoio aos cursos presenciais - disciplina ECF, pesquisa, entre outras) sem ainda discutir os capítulos do livro de textos por ele produzido. Na aula 02 aflorou, basicamente, a discussão sobre a concepção que não considera o papel da teoria no processo de construção do conhecimento científico e sobre a imagem que põe à vista o processo coletivo e cooperativo do fazer científico. Nessa aula ainda surgiu, assim como na aula 03, objeção à concepção na qual a evolução dos conhecimentos científicos é de crescimento linear (ignorando as confrontações entre teorias rivais e controvérsias científicas).

$\mathrm{Na}$ aula 03 ainda aflorou a concepção elitista do conhecimento científico e crítica à imagem metodologicamente rígida da ciência. Na aula 04 o debate girou, predominantemente, em torno da concepção na qual leis e teorias Físicas não são verdades fixas e imutáveis, mas sim provisórias até que sofram modificações ou surjam novas explicações. $\mathrm{Na}$ aula 05 , por sua vez, preponderou a discussão sobre a visão na qual a evolução dos conhecimentos científicos é alcançada com confrontações entre teorias rivais e controvérsias científicas, bem como que tais conhecimentos sofrem influência do contexto sociocultural da época.

A aula 06 voltou-se à discussão em torno da objeção à concepção que não considera o papel da teoria no processo de construção do conhecimento científico e à imagem metodologicamente rígida da ciência. A influência de fatores externos na disputa científica e a importância da base teórica no processo de construção do conhecimento científico, foram a tônica da aula 07 .

$\mathrm{Na}$ aula 08 (recortes em anexo) o debate concentrou-se no papel da experimentação num dado contexto histórico, sobretudo, na importância da base teórica. Já na aula 09 discutiuse a influência teórica nas observações científicas. $\mathrm{O}$ trabalho científico no que diz respeito às suas metodologias foi o foco da aula 10. A aula 11 pautou-se em torno da discussão entre o contexto da descoberta e o contexto da justificação.

$\mathrm{Na}$ aula 12 surgiram, preponderantemente, concepções sobre o papel da experimentação na construção do conhecimento científico, enquanto que, nas aulas 13 e 14, embora o texto/capítulo não fosse sobre a metodologia científica, predominaram concepções sobre esse tema a partir dos aspectos epistemológicos que a narrativa histórica transmite. Os comentários 
dos estudantes participantes das discussões da aula 14, por exemplo, desvelaram a visão de um suposto método científico como um conjunto de etapas a serem seguidas mecanicamente.

$\mathrm{Na}$ aula 15 afloraram concepções sobre os conhecimentos já elaborados e historicamente determinados acerca do trabalho coletivo e cooperativo, bem como acerca do papel da teoria no processo de construção do conhecimento científico. Na aula 16 a discussão girou em torno da imagem empírico-indutivista da ciência.

$\mathrm{Na}$ aula 17 o debate sobre a concepção na qual a evolução dos conhecimentos científicos não é imutável e é alcançada com confrontações entre teorias rivais e controvérsias científicas, sobressaiu-se em relação a discussão sobre o papel da teoria e do trabalho coletivo e cooperativo no processo de construção do conhecimento científico. A disputa científica, a influência teórica e o trabalho coletivo e cooperativo no processo de construção do conhecimento científico foram citados na aula 18.

$\mathrm{Na}$ aula 19 foi mencionada a objeção à imagem metodologicamente rígida da ciência e à concepção na qual a evolução dos conhecimentos científicos é de crescimento linear, ahistórica e individualista. $\mathrm{Na}$ aula 20 aflorou a contraposição à imagem metodologicamente rígida da ciência. Já nas aulas 21, 22 e 23 o debate, relativo à $\mathrm{NdC}$, concentrou-se na imagem empírico-indutivista da ciência, enquanto que na aula 23 ainda foi feita objeção à concepção aproblemática e individualista da ciência.

$\mathrm{Na}$ aula 24 as falas contrapuseram-se à imagem individualista e neutra da ciência e à concepção de um suposto método científico como um conjunto de etapas a serem seguidas mecanicamente. A aula 24 também tratou sobre o papel da teoria e das hipóteses no processo investigativo. Na aula 25 discutiu-se os critérios eliminatórios e de qualificação dos aspectos relativos à construção do conhecimento científico, presentes na ficha de avaliação do PNLEM/2009, disciplina Física, que vão ao encontro da concepção defendida ou problematizada pelo professor da disciplina ECF. Os estudantes presentes concordaram com tais critérios.

$\mathrm{Na}$ aula 26 a apresentação pautou-se no papel do experimento no contexto da época; na influência de um trabalho sobre outro; no papel da teoria e das hipóteses no processo investigativo e na unificação de conhecimentos. A importância dos experimentos para o desenvolvimento científico, a inexistência de um suposto método, o papel da teoria e das hipóteses no processo investigativo e a objeção à concepção aproblemática e a-histórica do conhecimento científico, foram mencionados na aula 27.

A aula 28 aflorou a objeção ao papel neutro (sem influência teórica) da observação sobre fenômenos. O diacronismo, a influência do contexto sociocultural de cada época na atividade científica e o processo de substituição de teorias aceitas por novas teorias, foram os temas debatidos na aula 29.

$\mathrm{Na}$ aula 30 mencionou-se a inexistência de um suposto método científico. Já na aula 31 prevaleceu a discussão sobre a visão individualista e elitista do conhecimento científico. Por fim, na aula 32 o foco, no que se refere à $\mathrm{NdC}$, foi o diacronismo, a metodologia científica e a evolução histórica do conhecimento científico. 


\section{Sobre a trajetória dos estudantes quanto às suas concepções sobre a NdC}

Conforme as observações sistemáticas das aulas, respostas dos estudantes ao questionário aplicado e os documentos da disciplina, os elementos, a seguir, foram determinantes para aflorar as concepções dos estudantes sobre a NdC e para influenciá-las, ainda que haja superposição entre eles:

a. Livro de textos;

b. Professor;

c. Contexto de sala de aula.

Dos 19 estudantes inscritos na disciplina, E2, E5, E6, E8, E14, E17, E18 e E19 não preencheram o questionário aplicado ${ }^{8}$. Os dados indicam que todos os estudantes se posicionaram pelo menos uma vez em concordância com aspectos relativos à visão de ciência defendida/problematizada pelo professor. Os licenciandos cursaram disciplinas obrigatórias que tratam do uso didático da abordagem histórico-filosófica, mas que não são voltadas unicamente à HFC (Instrumentação para o Ensino de Física A - IEFA e Didática Geral - DG), mas os bacharelandos, não.

Apesar disso, observou-se, a partir da análise dos questionários respondidos por E1, E3, E4, E7, E9, E10, E11, E12, E13, E15 e E16, que não há uma diferença significativa entre os estudantes que seguirão carreiras distintas quanto à receptividade ao material didático e às atividades de ensino, e como eles veem a $\mathrm{NdC}$ e percebem a importância da disciplina ECF na sua formação, com exceção de E3 que acha a HFC interessante, mas não necessária para o curso de bacharelado.

Conforme as informações prestadas no questionário (aplicado no final do semestre acadêmico 2012.1), os dados coletados a partir da plataforma moodle (sistema de apoio aos cursos presenciais) e as observações das aulas, os estudantes possuem um histórico de vivência sobre a NdC: fase final do curso de graduação, alguns com bolsa de iniciação científica, experiência com HFC (leitura independente, disciplina optativa de cunho histórico-epistemológico e/ou obrigatórias que tratam do uso didático da HFC).

Ainda assim, E8 e E11 revelaram, explicitamente, uma concepção que não concordava com a visão defendida/problematizada pelo professor, mas que apresentou mudança no decorrer da disciplina.

E8, nas aulas 04, 08 e 14, não concordava com a visão defendida/problematizada pelo professor, no que diz respeito à forma como se concebe a realização de uma dada investigação, mas na aula 23 mudou de ideia. Nessa aula, E8 fez objeção a visão que apresenta o "método científico" como um conjunto de etapas a seguir mecanicamente, uma discussão já recorrente, em maior ou menor grau, nas aulas 02, 03, 04, 05, 06, 08, 10, 12, 13, 14, 19 e 20.

\footnotetext{
${ }^{8}$ Conforme o TCLE, a participação dos estudantes na pesquisa foi de caráter livre e voluntário, não havendo nenhum tipo de obrigatoriedade para preencher, por exemplo, o questionário e/ou conceder entrevista.
} 
E11 também manifestou, explicitamente, uma concepção metodologicamente rígida do conhecimento científico. Na primeira parte da aula 14, E11 apresentava essa concepção. Contudo, na segunda parte da aula, E11 mudou de ideia após mediação do professor.

E1, E14 e E18 discordaram de outros aspectos relativos à visão de ciência defendida/problematizada pelo professor (E14 na aula 03; E1 e E18 na aula 29), mas não apresentaram um padrão de mudança no decorrer das aulas.

E2, E3, E4, E5, E7, E10 e E17 expuseram questionamentos e/ou posicionamentos ao longo das aulas que claramente sinalizavam concepções sobre a $\mathrm{NdC}$ em acordo com a visão do professor, mas no final da disciplina, aqueles que responderam o questionário (E3, E4, E7 e E10) revelaram, direta ou indiretamente, que tinham concepções "errôneas" sobre o fazer científico (concepção a-histórica, individualista e metodologicamente rígida do conhecimento científico), tendo como parâmetro a visão de ciência defendida/problematizada pelo professor.

Os outros estudantes (E6, E9, E12, E13, E15, E16 e E19), mesmo atentos às discussões de natureza histórico-epistemológicas que ocorreram durante as aulas, quase que não expuseram questionamentos e/ou posicionamentos, ao longo da disciplina, que explicitamente sinalizassem suas concepções sobre a NdC.

Portanto, as trajetórias individuais dos referidos estudantes, quanto às suas concepções sobre a $\mathrm{NdC}$, podem ser agrupadas da seguinte forma:

- estudantes que revelaram, explicitamente, uma concepção que não concordava com a visão defendida/problematizada pelo professor, mas que apresentou mudança ao longo da disciplina;

- estudantes que discordaram de aspectos relativos à visão do professor, mas não apresentaram um padrão de mudança no decorrer das aulas;

- estudantes que expuseram questionamentos e/ou posicionamentos ao longo das aulas, que claramente sinalizavam concepções sobre a $\mathrm{NdC}$ em acordo com a visão de ciência defendida/problematizada pelo professor, mas no final da disciplina, aqueles que responderam o questionário revelaram, direta ou indiretamente, que tinham concepções "errôneas" sobre o fazer científico, tendo como parâmetro a visão do professor;

- estudantes que mesmo atentos às discussões de natureza histórico-epistemológicas que ocorreram durantes as aulas, quase que não expuseram questionamentos e/ou posicionamentos, ao longo da disciplina, que explicitamente sinalizassem suas concepções sobre a $\mathrm{NdC}$.

Apesar do esforço do professor, as discussões em sala de aula não foram suficientes para fazer com que todos os estudantes participassem continua e espontaneamente dos debates (MASSONI; MOREIRA, 2007) e para que pudéssemos captar - mesmo que de participações esporádicas ou induzidas pelo professor e pelos demais estudantes - suas concepções sobre a $\mathrm{NdC}$. Esse papel foi complementado por atividades em grupo na sala de aula, pelos seminários apresentados pelos estudantes e pelas informações cedidas ao questionário aplicado. 
Os mapas de episódio mostram que as primeiras aulas da disciplina não forneceram elementos suficientes para supor que as concepções dos estudantes sobre a $\mathrm{NdC}$ eram "inadequadas" em relação à visão de ciência defendida/problematizada pelo professor ou fortemente associadas a imagem empirista/indutivista (MASSONI; MOREIRA, 2007). Talvez porque os textos discutidos na disciplina não remetam apenas à evolução histórica de conceitos científicos, mas também à problematização da NdC. Sua leitura, a priori, já influencia as trajetórias individuais dos estudantes no que diz respeito às suas concepções sobre o fazer científico.

Ao longo do semestre foi possível perceber que as falas e intervenções espontâneas dos estudantes sobre a NdC, concentraram-se em poucos deles, dentre eles, E8, E10, E11 e E18.

Isso, entretanto, não quer dizer que o livro de textos, o professor e o contexto de sala de aula não tenham sido adequados para fazer emergir as concepções dos estudantes que pouco participaram com falas e intervenções explícitas sobre aspectos relativos à $\mathrm{NdC}$, haja vista as respostas aos questionários e as diferentes concepções sobre a $\mathrm{NdC}$ que afloraram e foram discutidas repetidas vezes durante a disciplina.

\section{Conclusões}

A partir das trajetórias individuais dos estudantes, dos recortes das aulas da disciplina e dos questionários respondidos - pode-se concluir neste estudo, de caráter qualitativo e descritivo, que uma disciplina de natureza histórica, com perspectiva epistemológica, influencia fortemente as concepções dos estudantes sobre a $\mathrm{NdC}$, pois promove mudanças nessas concepções através da ação do professor em sala de aula, do material didático por ele produzido e do contexto.

A influência da disciplina ECF na formação de futuros profissionais em Física, no que diz respeito às suas concepções sobre a $\mathrm{NdC}$, evidencia-se ao longo das imagens de ciência que afloraram nas aulas e na forma como as discussões foram implementadas na sala de aula. Tal performance tem forte relação com a formação e experiência do professor no uso didático da HFC.

Com vistas às concepções dos estudantes sobre a NdC no decorrer da disciplina, podese também concluir que a reflexão sobre os aspectos relativos à visão de ciência defendida/problematizada pelo professor contribuiu significativamente na formação desses estudantes acerca da NdC.

No entanto, a partir deste estudo observa-se que a crença nas possibilidades de utilização da HFC como forma de transformar 'imagens distorcidas da ciência' de futuros profissionais em Física - ou proporcionar-lhes uma 'visão adequada da ciência' - deveria ser revista, pois o uso da HFC como forma de discutir concepções sobre a NdC mostrou-se mais coerente do que o uso da HFC na tentativa de transformar, corrigir ou evitar imagens consideradas distorcidas ou para proporcionar visões ditas mais adequadas.

Ainda assim, a discussão sobre os aspectos relativos à NdC não deveria ser realizada apenas em uma única disciplina obrigatória, como acontece no curso de graduação em Física 
em destaque, ou seja, essa discussão também deveria ter espaço em outras disciplinas de formação inicial, pois, os estudantes chegam à disciplina ECF com concepções sobre a NdC construídas/transformadas nas disciplinas de conteúdo científico (conceitual), na iniciação científica, nos eventos científicos, pela leitura independente etc. Contudo, as discussões nas disciplinas de conteúdo científico, em geral, são dissociadas da HFC e essa é associada apenas à disciplina ECF.

Portanto, há a necessidade de mais estudos sobre a $\mathrm{NdC}$ na formação de licenciandos e bacharelandos em Física - em diferentes contextos e em distintos lugares, utilizando instrumentos que também valorizem o processo vivenciado, seja em disciplinas de conteúdo científico, seja em disciplinas com foco no uso da abordagem histórico-filosófica - para respaldar a discussão aqui realizada.

\section{Referências}

ALTERS, B. J. Whose Nature of Science? Journal of Research in Science Teaching, v. 34, n. 1, p. 39-55, 1997.

AMANTES, A.; BORGES, O. Identificando fatores que influenciam a aprendizagem a partir da análise do contexto de ensino. Caderno Brasileiro de Ensino de Física, Florianópolis, v. 28, n. 2, p. 273-296, ago. 2011.

CORDEIRO, M. D.; PEDUZZI, L. O. Q. Um Módulo sobre a Radioatividade: Sua História e sua Transposição Didática. In: PEDUZZI, L. O. Q.; MARTINS, A. F. P.; FERREIRA, J. M. H. (Orgs.). Temas de História e Filosofia da Ciência no Ensino. Natal: EDUFRN, 2012. cap. 7, p. 183-210.

As conferências Nobel de Marie e Pierre Curie: a gênese da radioatividade no ensino. Caderno Brasileiro de Ensino de Física, Florianópolis, v. 27, n.3, p. 471-512, dez. 2010.

DANIEL, G. P.; PEDUZZI, L. O. Q. Tycho Brahe e Kepler na escola: uma contribuição à inserção de dois artigos em sala de aula. Revista Brasileira de Ensino de Física, São Paulo, v. 31, p. 3601-1-3601-10, 2009.

FERREIRA, J. M. H.; MARTINS, A. F. P. Avaliando a inserção da temática natureza da ciência na disciplina de História e Filosofia da Ciência para graduandos em Física na UFRN. In: PEDUZZI, L. O. Q.; MARTINS, A. F. P.; FERREIRA, J. M. H. (Orgs.). Temas de História e Filosofia da Ciência no Ensino. Natal: EDUFRN, 2012. cap. 6, p. 155-209.

FIGUEIRÊDO E PAULA, H.; BORGES, A. T. A compreensão dos estudantes sobre o papel da imaginação na produção das ciências. Caderno Brasileiro de Ensino de Física, Florianópolis, v.25, n.3, p. 478-506, dez. 2008. 
FORATO, T. C. M.; MARTINS, R. A.; PIETROCOLA, M. Enfrentando obstáculos na transposição didática da História da Ciência para a sala de aula. In: PEDUZZI, L. O. Q.; MARTINS, A. F. P.; FERREIRA, J. M. H. (Orgs.). Temas de História e Filosofia da Ciência no Ensino. Natal: EDUFRN, 2012. cap.5. p. 123-153.

GATTI, S. R. T.; NARDI, R.; SILVA, D. História da ciência no ensino de Física: um estudo sobre o ensino de atração gravitacional desenvolvido com futuros professores. Investigações em Ensino de Ciências, Porto Alegre, v. 15, n. 1, p. 7-59, 2010.

GIL PÉREZ, D.; MONTOR, I. F.; ALÍS, J. C.; CACHAPUZ, A.; PRAIA, J. Uma imagem não deformada do trabalho científico. Ciência \& Educação, São Paulo, v. 7, n. 2, p. 125 -154, 2001.

HÖTTECKE, D., SILVA, C. C. O. Why Implementing History and Philosophy in School Science Education is a Challenge: An Analysis of Obstacles. Science and Education, v. 20, p. 293-316, 2011.

IRZIK, G.; NOLA, R. New Directions for Nature of Science Research. In: MATTHEWS, M. R. (Editor). International Handbook of Research in Philosophy and Science Teaching. Netherlands: Springer. 2014. v. 2. p. 999-1022.

. A family resemblance Approach to the Nature Sicence for Science Education. Science and Education, V.20, n. 5, p. 591-607, 2011.

KÖHNLEIN, J. F. K.; PEDUZZI, L. O. Q. Uma discussão sobre a natureza da ciência no ensino médio: um exemplo com a teoria da relatividade restrita. Caderno Brasileiro de Ensino de Física, Florianópolis, v. 22, n. 1, p. 36-70, abr. 2005.

LEDERMAN, N. G. Students' and teachers' conceptions of the nature of science: a review of the research. Journal of Research in Science Teaching, New York, v. 29, n. 4, p. 331-359, 1992.

LEDERMAN, N. G. Teachers' understanding of the nature of science and classroom practice: factors that facilitate or impede the relationship. Journal of Research in Science Teaching, New York, v. 36, n. 8, p. 916-929, 1999.

LONGHINI, M. D.; NARDI, R. Como age a pressão atmosférica? Algumas situações-problema tendo como base a História da Ciência e pesquisas na área. Caderno Brasileiro de Ensino de Física, Florianópolis, v.26, n.1, p.7-23, abr. 2009.

MARTINS, A. F. P. História e Filosofia da Ciência no Ensino: há muitas pedras nesse caminho... Caderno Brasileiro de Ensino de Física, Florianópolis, v. 24, n. 1, p. 112-131, abr. 2007. 
MASSONI, N. T.; MOREIRA, M. A. Ensino de Física em uma escola pública: um estudo de caso etnográfico com um viés epistemológico. Investigações em Ensino de Ciências, Porto Alegre, v. 17, n. 1, p.147-181, 2012.

- O Cotidiano da Sala de Aula de uma Disciplina de História e Epistemologia da Física para Futuros Professores de Física. Investigações em Ensino de Ciências, Porto Alegre, v. 12, n. 1, p.7-54, 2007.

MATTHEWS, M. In defense of modest goals when teaching about the nature of science. Journal of Research in Science Teaching, New York, v. 35, n. 2, p. 161-174, 1998.

MORAES, R.; GALIAZZI, M. C. Análise textual discursiva. Ijuí: Ed. Unijuí, 2013. 224p.

MOREIRA, M. A.; MASSONI, N. T.; OSTERMANN, F. "História e Epistemologia da Física" na licenciatura em Física: uma disciplina que busca mudar concepções dos alunos sobre a natureza da ciência. Revista Brasileira de Ensino de Física, São Paulo, v. 29, n. 1, p. 127-134, mar. 2007.

OLIVEIRA, R. A.; SILVA, A. P. B. História da Ciência e Ensino de Física: Uma Análise MetaHistoriográfica. In: PEDUZZI, L. O. Q.; MARTINS, A. F. P.; FERREIRA, J. M. H. (Orgs.). Temas de História e Filosofia da Ciência no Ensino. Natal: EDUFRN, cap.2. p. 41-64. 2012.

PEDUZZI, L.O. Q.; TENFEN, D. N.; CORDEIRO, M. D. Aspectos da Natureza da Ciência em animações potencialmente significativas sobre a História da Física. Caderno Brasileiro de Ensino de Física, Florianópolis, v. 29, n. Especial 2, p. 758-786, out. 2012.

PEREIRA, G. J. S. A.; MARTINS, A. F. P. A inserção de disciplinas de conteúdo históricofilosófico no currículo dos cursos de licenciatura em Física e em Química da UFRN: uma análise comparativa. Caderno Brasileiro de Ensino de Física, Florianópolis, v. 28, n. 1: p. 229258, abr. 2011.

TEIXEIRA, E. S.; GRECA, I. M.; FREIRE JR, O. Uma revisão sistemática das pesquisas publicadas no Brasil sobre o uso didático de História e Filosofia da Ciência no ensino de Física. In: PEDUZZI, L. O. Q.; MARTINS, A. F. P.; FERREIRA, J. M. H. (Orgs.). Temas de História e Filosofia da Ciência no Ensino. Natal: EDUFRN, 2012b. cap.1 p. 9-40.

VILAS BOAS, A.; SILVA, M. R.; PASSOS, M. M.; ARRUDA, S. M. História da Ciência e Natureza da Ciência: debates e consensos. Caderno Brasileiro de Ensino de Física, Florianópolis, v. 30, n. 2, p. 287-322, ago. 2013.

VITAL, A.; GUERRA, A. A Natureza da Ciência no ensino de Física: estratégias didáticas elaboradas por professores egressos do mestrado profissional. Caderno Brasileiro de Ensino de Física, Florianópolis, v. 31, n. 2, p. 225-257, ago. 2014. 


\section{Anexo}

\section{Recortes da aula 08}

Conforme o professor e autor do livro-texto intitulado "Força e movimento: de Thales a Galileu", o capítulo 6 (A física de Galileu) apresenta as primeiras ideias desse sábio italiano sobre força e movimento e a influência de Arquimedes em seu trabalho; mostra como Galileu obtém a lei da queda dos corpos, introduzindo, definitivamente, uma física quantitativa, inteiramente diferente da física das qualidades de Aristóteles e de seus seguidores, e da física do impetus, bastante confusa e vaga; e discute o movimento de projéteis e a inércia galileana, chamando a atenção que esta última seria, no limite, uma inércia circular.

Para tanto, o capítulo 6 foi dividido nos seguintes subcapítulos: Introdução, As primeiras ideias de Galileu sobre força e movimento, A influência de Arquimedes e a lendária experiência da torre de Pisa, O movimento acelerado e a queda dos corpos, $\mathrm{O}$ movimento neutro e a lei da inércia de Galileu, A questão do movimento de um projétil em um navio em movimento, Galileu e o movimento de projéteis.

A seguir a discussão do capítulo 6 do livro de textos intitulado "Força e movimento: de Thales a Galileu" - A física de Galileu: contexto (C), isto é, perguntas, opiniões, posicionamentos e/ou comentários do(s) estudante(s) (E) e do professor (P) decorrentes dessa discussão.

$\mathrm{C}$ : Comentários e posicionamentos após o professor realizar a leitura do texto acerca da lendária experiência da torre de Pisa:

E14: (...) o senhor imagina... o senhor se imagina... se o senhor fosse professor da universidade e que nessa universidade ... todo conhecimento científico que até então... o senhor estava consciente do que estava acontecendo ... existem conhecimentos bem definidos ... que até então são incontestáveis... o senhor... aceitaria um convite de um louco que tentaria mudar todo este conhecimento que o senhor... já está bem... bem estabelecido com o senhor... o senhor aceitaria o convite de um louco para ir lá no alto da torre... e ver fazer um experimento... tentar... será que não... será que o senhor aceitaria... mas o senhor concorda com tudo isso que está escrito neste livro... é isso (...)

P: (...) o aparecimento da ciência exata ... só com experiências para se fazer isso (...)

C: Questão frente a discussão sobre a lendária experiência da torre de Pisa:

P: (...) mas para ser ciência experimental não tem que ser... por experimentos ou ela nasce do nada... só da ficção... da Filosofia? (...)

E17: (...) tem uma base teórica (...)

E1: (...) tem uma parte teórica ... mas para ser ciência experimental... tem que tentar (...)

E8: (...) um outro texto em que... esteja em voga o que a comunidade científica aceita como correto naquele momento (...)

E1: (...) a questão para mim é que a experiência... é uma lenda (...)

E7: (...) sem contar que parece que foi de um dia para o outro (...) 
E3: (...) mas é importante levar este texto..., mas não sem apresentar a teoria ... apresentar o que o Galileu estava fazendo porque se não vai parecer que foi do dia para o outro (...)

E2: (...) eu acho que... uma coisa ... ela não surge do nada (...)

E10: (...) ele já tinha uma ideia (...)

P: (...) então as coisas não saem do nada... não aparecem de uma hora para outra (...)

E18: (...) e aí começar a abrir como é que foi a ideia de Galileu (...)

E18: (...) e ele veio com essa ideia do nada.... vocês teriam ideia do dia para noite e iriam convocar todo mundo para mostrar (...)

E18: (...) ele com certeza passou por muitas provocações... ele fez vários testes... fez vários experimentos... tem toda uma teoria bolada... a gente poderia dai mostrar... qual o potencial intuitivo... por que a gente não fala no texto... qual que era a teoria que tinha na época... por que ela era tão bem aceita... onde é que estava a diferença dela para teoria de Galileu (...)

E18: (...) se ele fosse fazer um experimento diferente... ele poderia quebrar a cara... ele não fez... mas será que o Galileu não faria diferente... você como um físico experimental ... você tentaria provar uma teoria completamente... então será que este experimento tem realmente alguma realidade... ele ia chamar todo mundo para ver um pouquinho... não ia apresentar nenhuma teoria ... o interessante... eu acho isso... trabalhar toda essa evolução do conceito dele... e também na parte que também tinha um erro... ia mostrar... teve uma parte que ele está correto... foi uma evolução... mas ele também não foi o ápice... ele não foi o ponto que a gente chegou e realmente montou outra teoria (...)

E2: (...) a questão também da física experimental... eu acho que é importante ressaltar que... ele para de investigar a causa dos movimentos... para investigar o movimento... em si... então tu para fazer isso você tem que analisar com equipamento... com alguma coisa (...)

E4: (...) genial a ideia também ... é genial (...)

E3: (...) você chegar só com este texto sem teoria nenhuma ... você simplesmente mostra e diz que é verdade... isso você não pode fazer ... você teria que mostrar ... dar uma teoria... e dizer o que está por trás do Galileu... você pode chamar ele de pai da experimentação... não só com base... só com este texto (...)

P: (...) aonde surgiu a ideia do plano inclinado... teve a ideia ... foi original o plano inclinado... mas nasceu do nada... nasceu do nada ... foi tudo ideia dele ali ... não? (...)

E2: (...) se ele fez o experimento tinha alguma coisa em mente (...)

P: (...) mas isso aí já tinha sido... objeto de estudo... por outros matemáticos ... algum tempo atrás... o Galileu retoma... as pessoas fazem uso do conhecimento de outras ... claro... não tem que reconstruir tudo... a partir do zero... construir tudo a partir do zero (...)

E10: (...) tem que pensar a natureza sempre da forma mais simples (...)

P: (...) e aí tem uma intuição correta... não é (...) 
P: (...) parece que tu dás bem uma aula... está bem contextualizado... fala que ele não está sozinho... muda de... pensamento com o tempo... tem um deslocamento... a pessoa não pensa sempre do mesmo jeito... tem diferentes concepções ... evoluem ... ainda bem (...)

E17: (...) não se sabe se não é verdade com certeza também (...)

E1: (...) com certeza absoluta não... mas tem bastante evidências (...)

E17: (...) o cara fez um pensamento lógico ali... lógico... ele fez uma estrutura lógica ... e chegou a uma conclusão..., mas por outro lado é um aluno do Galileu... por que então ele também... ficaria inventando... cara (...)

E1: (...) mas como só ele faz menção... o próprio Galileu não faz menção... a essa experiência... então para mim é muito duvidoso (...)

P: (...) qual o papel da experimentação na física do Galileu? (...)

E7: (...) eu acho que ele dá validade a teoria dele (...)

C: Comentários e posicionamentos em resposta a seguinte colocação do professor: Galileu parte do experimento e a partir daí, do nada, chega a alguma coisa, ou usa o experimento para corroborar?

$\mathrm{E} 8(. .$.$) eu acho que em momentos ele observou a natureza acontecendo e tentou for-$ mular... e em momentos ele pensou em alguma coisa e tentou experimentar (...)

P: (...) para tentar corroborar com uma ideia já pensada ... a simplicidade da queda livre (...)

E8: (...) ele tentou corroborar porque percebeu que acontecia na natureza (...)

E8: (...) a pergunta do senhor era se ele partia da experiência ou se ele partia do pensamento (...)

E13: (...) ninguém parte do experimento do nada ... assim (...)

P: (...) ninguém parte do experimento do nada (...)

E11: (...) uma coisa é visualizar ... outra coisa é fazer o experimento (...)

E13: (...) foi um experimento... que não foi intencional (...) (Posicionamento de E13 para E3 ao se referir à descoberta de Oersted)

E3: (...) utilizou o experimento para corroborar ... pronto ... todo mundo concorda (...)

E7: (...) é fundamental se ele fez também ... que ai ele quebra ... ele faz a diferenciação entre Física e Filosofia mesmo... neste ponto ele começa a experimentar... partir de uma ideia... botar em prática para mostrar alguma coisa (...)

P: (...) tem a experimentação... tem a matematização... isso tudo difere muito do conhecimento que... está lá para trás (...)

$\mathrm{C}$ : Resposta dada pelo professor à E7 quando o mesmo perguntou se Galileu trabalhava em várias áreas do conhecimento simultaneamente. Mas que nesse instante da história Galileu estava pensando na Astronomia e na Física:

P: (...) e ali a gente vê que ele adere a teoria do impetus... que depois tem influência do Arquimedes sobre ele... então essas coisas vão se dando ao longo do tempo (...) 
$\mathrm{C}$ : Aqui o professor pediu para que os estudantes fizessem um resumo sobre os principais pontos do capítulo 6 (A física de Galileu), ou melhor, pediu aos estudantes que dissessem o que estava por trás de tudo que foi exposto:

E11: (...) você tem que contextualizar o texto (...)

E17: (...) A contextualização filosófica que é importante... citar Aristóteles e o conceito todo... dele... foi de grande importância para a evolução mesmo do trabalho dele(...)

E17: (...) falar de todos os experimentos de maneira geral assim... como ele trabalhou... o que ele usou... que foi um método assim interessante de medida... falar também do erro de medida que estava associado também ao método dele... depois as implicações ideias devido a experimentação (...)

E10: (...) simplicidade... a explicação mais simples da natureza (...)

P: (...) seria um pressuposto... porque eu vou achar que a natureza se comporta da forma mais complexa se... ai nem vou estudar... nem vou desenvolver meu trabalho... vai ser dificil para mim (...)

E11: (...) deixar claro que nada surgiu do nada ... ele demorou a vida inteira (...)

E7: (...) e trabalhou em várias áreas não só em uma área... não só em uma área específica (...)

P: (...) que demora tempo para se construir alguma coisa (...)

E17: (...) que ele se transforma com o tempo... que ele adquire (...)

E5: (...) que ele é falivel (...)

P: (...) que ele é falivel... ele erra... ele mudou de opinião... então viu que estava equivocado em certas coisas... então não tem nada de ser perfeito que... funciona tudo sempre direitinho (...)

E18: (...) o senhor estava falando que a natureza não devia ser muito complexa não é (...)

P: (...) tá... mas a gente pensa a ideia de que hoje a natureza é simples (...)

E18: (...) A gente sabe... a gente cria modelos para tentar explicar o que o que está acontecendo (...)

E4: (...) por que é que eu tenho que fazer isso... porque ela é complexa... não porque ela é simples... ela não sabe criar modelos (...)

E17: (...) o que ajudou ele desenvolver foi a observação objetiva da realidade... então no fundo... essa parte pragmática da realidade... essa objetividade da realidade ... que vai dar a última palavra na decisão de um corpo teórico (...)

E8: (...) dá para dizer que ele foi o pai do método científico também (...)

P: (...) o que seria o método científico (...)

P: (...) a insatisfação com um conhecimento não começa com um problema (...)

E10: (...) apesar dele usar muitas ideias dos outros... ele não era muito influenciado pelas ideias que estavam estruturadas... ele tinha a capacidade de olhar criticamente para uma coisa que estava estabelecida... e pensar de outra forma (...) 
P: (...) tem que ter coragem para se contrapor... quantos não concordavam e ficaram calados e tal... bom... foram esquecidos (...)

P: (...) então vocês veem que o Galileu não é simples... que não tem uma versão única sobre o Galileu (...) 